adequate alternative provision exists for the patients. Current discharge polices often send patients out into the community (at times back onto the streets) so rapidly that no appropriate arrangements for aftercare can possibly be made. This causes much suffering not only for those directly involved, but also for their families. The move to speed up the discharge process is causing great anxiety, not only to relatives, but also to those in our organizations who work in the field, and who consider the present situation totally unsatisfactory.

We are convinced that these policies need review as a matter of the utmost urgency, and that new, innovative, but realistic plans should be made, based on a far more searching assessment of the numbers of those in need, the degree and nature of their problems or disabilities, the kind of alternative service needed, the time it will take to provide the service, and the agency which will provide it.

We should be grateful for your comments. I should add that we have consulted the Church Army, who have also seen our statement, and they have similar difficulties in working with those patients discharged from mental hospitals into their large hostels.

Yours sincerely, JOYCE MAJOR

Chairman

\section{Statement agreed by National Schizophrenia Fellowship and Richmond Fellowship}

1. Those suffering from mental illness have varying needs, depending on their own wishes and the course of their illness. The following statement, drawn up by the National Schizophrenia Fellowship, in consultation with other organizations, concentrates on the problems of people suffering from schizophrenia, a very common illness, which affects one in every hundred people. More patients are in hospital because of schizophrenia than as a result of any other medical or surgical condition.

2. Any plan to close mental hospitals directly affects both those afflicted and those who care for them, and this joint statement is made in the first instance in response to the planned closure of Banstead, Norton, Friern, Claybury, Long Grove and West Park hospitals, just outside London. But it applies to many other areas.

3. Of those affected by schizophrenia, often young people, 20-25 per cent are likely to recover rapidly and will probably maintain themselves throughout their lives with little further help. Another 50-60 per cent may well be able to live outside hospital, but will need support of many different kinds. The remaining 20-25 per cent require so much care, probably on a long-term basis, that hospitals are at present the only places able to look after them.

4. Government policies outlined in the 1981 Green Paper, Care in the Community, and the Government statement on
12 July $1983^{*}$, that it seemed likely that many large isolated psychiatric hospitals will prove redundant, will almost certainly force many mentally ill patients into the community without adequate care. It should not be forgotten that there is no certain cure for severe mental illness, and in some cases lifelong disablement results, to a greater or lesser degree, despite modern drug treatments.

5. We are agreed:

(i) That services for the mentally ill outside hospital are totally inadequate in many parts of the country. The majority of mental patients who have been seriously ill are accepted on discharge into their homes by relatives, who then try to cope with sometimes bizarre, violent or potentially suicidal situations with little or no support. This is what care in the community usually means. Many former patients without families, or whose families reach breaking point, get no care at all, and end up in prison or mental hospital, as vagrants, or commit suicide.

(ii) That the provision of hostels, group homes, etc. is insufficient, and where hostels exist they are often underutilized because no public authority will pay the fees.

(iii) That it is often very difficult indeed to obtain hospital admission for people who, without doubt, are in desperate need of in-patient treatment.

6. We therefore urge the Government:

I (i) To give shelter and care to those most mentally disabled in the only places properly equipped to provide itour psychiatric hospitals - unless or until other adequate alternatives actually exist. Though local health and social services authorities are legally obliged to provide aftercare, what this should include has not yet been identified in statutory terms.

(ii) To reject the idea that the life of a long-stay mental hospital patient is necessarily worse than life as a homeless vagrant, which is for many the only alternative. The patient does not choose to leave the asylum provided by a psychiatric hospital, in many cases, but is compelled to leave.

(iii) To give backing to staff manning this essential service both with adequate resources, and by in-service training, so that morale, now lowered by incessant threats of closures and by a running fire of ill-informed criticism, can be restored.

(iv) To ask psychiatrists to modify the widespread Open Door Policy, not by returning to the past, when every mental hospital ward was locked, but by recognizing that some secure accommodation is required in most health districts for the relatively few people who need it. We believe present policies often lead to prison sentences for the mentally ill, and to a refusal by the hospitals to admit those most in need of treatment. We do not think the planned provision of regional secure units will fully solve this problem.

"Lord Glenarthur, Minister at the DHSS with special responsibility for mental health matters, replying to a Parliamentary Question from Lord Mottistone. 
II (i) To support those psychiatrists and social workers trying to implement carefully planned discharged policies. We want discharge to a known address, and to a caring person, and a continuing liaison with the medical and social services. This could be far more cost effective than precipitate discharge resulting from excessive pressure to reduce in-patient beds. Too rapid discharge, and consequent re-admission to hospital (see 5(iii) above)-if re-admission is possible-make any chance of rehabilitation more difficult to achieve.

(ii) To expand the Community Psychiatric Nursing Service so that it is available to the mentally ill all over the country, and also to relatives and others providing accommodation and day to day care. This service, which has the confidence of all, should improve access to specialized medical help, including hospital re-admission, where the condition of the patient worsens beyond the ability of families and others to cope. Hospital catchment area boundaries should not be used as barriers to admission for treatment.

(iii) To support vigorously and financially various kinds of realistic alternatives to hospital provision, now often in outworn buildings (which may be provided by local authorities, voluntary bodies or families), bearing in mind that: (a) a minority of patients will need a very great deal of hospital or hostel care, with high staffing levels, which may well be required on a lifelong basis; (b) that a good number of patients living in the community will be unable to maintain themselves without ongoing and caring support; and (c) that many patients suffering severe emotional distress need easy access to short-term good quality hostel care.

\section{Correspondence}

\section{Hospital records and psychiatric memorabilia}

DeAr SirS

I was interested to see Martin Guha's article on 'Archives and Historical Libraries in Psychiatry' (Bulletin, February $1984,8,25)$. As custodian of what he kindly refers to as 'almost certainly the largest collection of this sort of material in this country', I would like to add some further information.

Almost by the way, the historical book collection at the Institute of Psychiatry was originally based not on Willi Mayer-Gross's library, though that may have provided the bulk of it, but on the library of Henry Maudsley himself. This was presumably the source of, for example, the association's copies of books formerly belonging to his father-in-law, John Conolly. Following Maudsley's specific wishes, over 200 of his 'philosophical, psychological and medical works', together with a bust of Shakespeare and 15 framed prints of 'distinguished alienists' were given to the Maudsley Hospital after his death by his nephew and executor. They were selected by Sir Frederick Mott, and the books were intended to be kept in a specially inscribed case as a memorial to him. Unfortunately they seem now to have been dispersed among the rest of the historical books by $\mathrm{Mr}$ Guha's predecessors, which is particularly sad in view of the singular lack of personal information about Henry Maudsley. The real value of association copies is not in the signature at the front, but in what they can tell of the owner's intellectual pursuits and interests, and the influences behind his own work, and to have been able to reconstruct at least part of Maudsley's library would have been very useful to his would-be biographers.

Mr Guha's references to 'collections' of archives and 'archival and historical collections' might be slightly misleading. Archives are simply the accumulated records of an organization or an individual, and are quite different from the artificial collections of manuscripts which are often to be found in libraries. Thus the archives here are no more nor less than the historical records of Bethlem itself and of the Maudsley: they are only larger than most psychiatric hospital archives because Bethlem is very old, and paper does tend to mount up!

The records of psychiatric hospitals, as of all NHS hospitals, are Public Records, and subject to the provisions of the Public Records Act 1958. The archives of individual hospitals should therefore not be difficult to locate, if the rules have been followed. If they have not been destroyed (and destruction is generally not in accordance with the rules), they should be either still in the hospital, or deposited in a place appointed by the Lord Chancellor as a repository for Public Records - in this case usually the County or other Local Record Office. Bethlem, as one of the only two hospitals in the country to employ a full-time professional archivist, has been appointed as the official repository of its own records, otherwise they would probably be in the Guildhall Library or the GLC Record Office.

Of course, should one apply first to the hospital itself, getting anyone to admit to knowing where the archives are is a different matter: it is therefore probably wise to start with the relevant County Record Office. There has lately been a considerable effort by local archivists to establish contact with the hospitals in their areas, and even if the records have not actually come into the Record Office, they will often know what is available and where. Local Record Offices sometimes also contain other material of interest to historians of psychiatry, such as the records of private 